\title{
CURSOS DE EDUCAÇÃO E FORMAÇÃO: \\ UMA OPORTUNIDADE PARA QUESTIONAR PRÁTICAS DE SALA DE AULA E RECONSTRUIR IDENTIDADES ESCOLARES
}

\author{
Mónica Baptista*; Sofia Freire**; \\ Carolina Carvalho***; Ana Freire***; \\ Mário Azevedo****; Teresa Oliveira*****
}

RESUMO: Este estudo tem como objectivo conhecer o impacto de actividades investigativas em aulas de Física e Química na reconstrução de identidades escolares. Estudaram-se três turmas do ensino secundário de um curso de Educação e Formação. Participaram 28 alunos, com histórias pesadas de insucesso escolar, aos quais se fez uma entrevista em grupo focado. Recorreu-se a um método de análise de conteúdo. Os dados sugerem um percurso, inicial, feito de insucessos, assente em identidades escolares negativas, que não sendo passíveis de ser re-avaliadas ou restauradas, geram vontade de abandonar a escola. Para além disso sugerem que novas experiências pedagógicas e curriculares podem facilitar a reconstrução dessas identidades e a emergência de novas formas de se relacionar com a escola e com o saber escolar.

Palavras-chave: Educação em Ciências; Investigações Científicas; Abandono Escolar; Identidade.

\section{CURRICULUM FOR PROFESSIONAL EDUCATION AND TRAINING: AN OPPORTUNITY TO QUESTION INSTRUCTIONAL PRACTICES AND TO RECONSTRUCT SCHOOL IDENTITY}

ABSTRACT: This study aims at understanding the impact of investigative activities in Physics and Chemistry classes in the reconstruction of school identities. Three secondary classes of a professional education and training course were studied. 28 pupils with dramatic school failure records participated and were submited to focus groups interviews. A method of content analysis was carried in order to study quality of answers and arguments presented. Data suggest that students' negative school identities, which cannot be re-evaluated in current school context, make them unwilling to learn and consider dropping out school. Besides, new curricular and pedagogical experiences can facilitate school identity reconstruction and also the emergence of new ways to relate to school and to school knowledge.

Keywords: Science Education; Inquiry Activities; Identity; Dropping out.
${ }^{*}$ Doutora em Educação pelo Instituto de Educação da Universidade de Lisboa. Professora no Instituto de Educação da Universidade de Lisboa. E-mail: mbaptista@ie.ul.pt **Doutora em Educação pelo Instituto de Educação da Universidade de Lisboa. Professora no Instituto de Educação da Universidade de Lisboa. E-mail: asraposo@ie.ul.pt

** *Doutora em Educação pelo Instituto de Educação da Universidade de Lisboa.

Professora no Instituto de Educação da Universidade de Lisboa. E-mail: cfcarvalho@ie.ul.pt * * * Doutora em Educação pelo Instituto de Educação da Universidade de Lisboa.

Professora no Instituto de Educação da Universidade de Lisboa. E-mail: amvfreire@ie.ul.pt Doutor em Educação pelo Instituto de Educação da Universidade de Lisboa.

Professor no Instituto de Educação da Universidade de Lisboa. E-mail: mdazevedo@ie.ul.pt ******Doutora em Educação pelo Instituto de Educação da Universidade de Lisboa. Professora no Instituto de Educação da Universidade de Lisboa. E-mail: mtoliveira@ie.ul.pt 
A educação formal assume um papel central nos dias de hoje. Com efeito, em vários documentos políticos a educação passou a ser entendida como forma de construir um mundo melhor, mais próspero, tolerante e solidário e, simultaneamente, como condição necessária para se promover o desenvolvimento pessoal (CONSELHO DA EUROPA, 2006b, 2007; UNESCO, 2000, 2003). Assim, a educação é hoje em dia considerada como um direito fundamental que não pode ser negado a ninguém, com o perigo de excluir todos aqueles que não se apropriarem das competências que são hoje consideradas essenciais para lidar e viver numa sociedade complexa, multifacetada, dinâmica e mutável como é a nossa (CONSELHO DA EUROPA, 2006a; GALVÃO et al, 2006; NRC, 2000; PERRET-CLERMONT, 2004; UNESCO, 2003).

Mas, à medida que aumentam as expectativas com a educação e as exigências de um ensino de qualidade para todos, aumentam (ou tornam-se mais visíveis) os casos de insucesso (CONSELHO DA EUROPA, 2006b, 2007; UNESCO, 2000, 2003). A escola construída para todos afinal não está a dar resposta a todos. Com efeito, para além do número significativo de alunos que, de forma generalizada, abandonam precocemente a escola (AINSCOW \& FERREIRA, 2003), há ainda a referir a descrença generalizada em relação aos saberes escolares e à sua utilidade, bem como em relação aos diplomas escolares, e, ainda o grande desinvestimento na escola (CANÁRIO et al, 2001; RESNICK \& PERRETCLERMONT, 2004; SMITH, 2006). No caso português, é de salientar que este fenómeno se manifesta de uma forma mais aguda entre aqueles provenientes de meios sociais e geográficos mais desfavorecidos (BARROSO, 2003; CANÁRIO, 2000; CNE, 2007; MINISTÉRIO DA EDUCAÇÃO, 2006).

Esta situação coloca grandes desafios aos diferentes sistemas educativos, em particular ao sistema português, que, apesar de melhorias recentes nesta situação, apresenta taxas de retenção e de abandono escolar ainda significativas (GEPE, 2010). No sentido de garantir uma educação de qualidade para todos, têm sido envidados esforços legislativos, quer através da reforma curricular (Decreto-Lei n. 6/2001 de 18 de Janeiro), visando flexibilizar as estratégias de ensino e a gestão dos recursos e do currículo, quer ainda através do alargamento de modalidades formativas para os alunos do Ensino Básico e secundário. No âmbito da reorganização curricular, foram definidas novas orientações para $\mathrm{O}$ ensino das Ciências (MINISTÉRIO DA EDUCAÇÃO, 2001, 2003), enfatizando o desenvolvimento de abordagens construtivistas, centradas no aluno, e o desenvolvimento de actividades investigativas como forma de facilitar a aprendizagem de e sobre a Ciência (BYBEE, 2006; COMISSÃO EUROPEIA, 2007; GOMES et al, 2008). No âmbito do alargamento de modalidades formativas, é de referir a criação dos cursos de Educação e Formação (Despacho-Conjunto n. 453/2004, de 27 de Julho) destinados, preferencialmente, a jovens com idade igual ou superior a 15 anos, em risco de abandono escolar ou que já abandonaram a escola, com o objectivo de proporcionar uma formação escolar e qualificação profissional e facilitar o seu ingresso na vida activa. 
Ambas as iniciativas legislativas constituem uma oportunidade para desafiar aspectos cognitivos e sociais frequentemente associados à experiência escolar e associados ao desinvestimento na escola e, mesmo, ao abandono escolar. Com efeito, estudos centrados no modo como os alunos constroem as suas identidades enquanto alunos e de como essas identidades moldam as suas relações com a escola e com o saber escolar (FREIRE et al, 2009a, MATTOSS, 2005), revelam que alunos provenientes de meios mais adversos são reificados em posições desfavoráveis, que legitimam formas de interpretar e de responder aos seus comportamentos, originando situações de não participação. Estas situações, ao não permitirem aos alunos negociar significados sobre a sua experiência, mantêm o ciclo de reificação - não participação, que conduz, eventualmente, à exclusão destes alunos do sistema educativo e ao seu desinvestimento na escola. Outros estudos suportam estes resultados. Por exemplo, Smith (2006) refere que

Ser bem sucedido na escola significa, para muitos alunos, ter que suprimir as suas próprias identidades e agir de acordo com uma visão pré-definida, institucional, constringida, sobre o que é ser um "bom" aluno. Para muitos alunos ir para a escola envolve um tipo de trabalho identitário particular e difícil - negociar/ suprimir as suas próprias identidades. As escolas oferecem a possibilidade de independência futura e oferecem, também, os recursos conceptuais que podem contribuir para a construção de algumas identidades. Contudo, a luta pela identidade, na escola, pode ser difícil para alguns alunos. Para aqueles que desistem, a escola perdeu, efectivamente, o seu potencial para contribuir para os seus planos de vida. A escola deixou de ser vista como um espaço viável para fazer o trabalho identitário. (p. 290, tradução do autor)

A criação de "espaços de pensamento" (PERRET-CLERMONT, 2004), nos quais os alunos possam, de uma forma segura, negociar um sentido para a sua experiência, através da interacção e da partilha e através da apropriação de conhecimento relevante, são essenciais para facilitar a reflexão sobre quem são. Pelas suas características, as actividades investigativas nas aulas de Ciência podem constituir-se enquanto "espaços de pensamento" e facilitar a reflexão dos alunos sobre a sua experiência e sobre quem são enquanto alunos (FREIRE et al, 2009b). Num outro sentido, as novas modalidades formativas (nomeadamente os cursos de Educação e Formação), ao constituírem-se como contextos privilegiados para se ensaiarem novas formas de pedagogia, facilitam a vivência de experiências educativas que poderão facilitar a quebra do ciclo reificação - não participação - exclusão (Freire et al, 2009b).

Tendo em conta que o número de alunos que procuram outras modalidades educativas fora do âmbito regular de ensino se encontra a aumentar (GEPE, 2010) e a necessidade de se modificar identidades escolares dos alunos como forma de facilitar o seu re-investimento na escola (FREIRE et al,2009b), torna-se extremamente importante conhecer as identidades escolares dos alunos quando ingressam num curso de Educação e Formação e o impacte que a experiência com novas formas de pedagogia podem ter a nível da mudança dessas identidades e nos sentidos que dão ao seu percurso escolar presente e futuro. 
Este artigo teve, pois, como objectivos conhecer o modo como os alunos descrevem o seu percurso escolar passado, quais as suas expectativas em relação ao percurso escolar futuro, como percepcionam a sua experiência no curso de Educação e Formação e nas aulas de Ciência nas quais foram utilizadas actividades investigativas e, finalmente, conhecer a forma como se percepcionam e como pensam que os outros os percepcionam, procurando relacionar a sua experiência escolar com mudanças nas suas percepções e expectativas.

\section{IDENTIDADE ESCOLAR E RELAC̣ÃO COM A ESCOLA E COM O SABER ESCOLAR}

A aprendizagem e o desenvolvimento ocorrem em contextos sociais e culturais, que estão em constante mudança, e que influenciam e são influenciados pelas interacções, modos de perceber os outros e a situação, e pelas próprias práticas que se desenvolvem no seu seio (PALINSCAR, 1998, PERRETCLERMONT, 2004; ROGOFF \& LAVE, 1984). Segundo esta perspectiva, os alunos não se apropriam apenas conhecimento académico, mas desenvolvem também novas formas de estar, de se percepcionar (e aos outros) e de se relacionar com os outros e com o saber (GOMES \& MORTIMER, 2008; GUTIERREZ et al, 1995; HAND, 2006; LAVE \& WENGER, 1991; NASIR, 2002; SOLOMON, 2007; WENGER, 1998).

Assim, é essencial considerar não só os aspectos cognitivos, mas também os aspectos afectivos envolvidos no processo de aprender. Com efeito, ao interagir com os outros (pares, professores) e, mesmo, manuais escolares, o aluno é confrontado com diferentes saberes, que pode explorar e/ou elaborar, apropriando-se de novas competências e modificando a sua estrutura conceptual. Simultaneamente, é também pelo confronto com o outro que o aluno constrói uma identidade escolar, englobando imagens sobre quem ele é como aluno, sobre o que é conhecimento válido e sobre o que é aprender, que podem ser determinantes na forma como se vai relacionar com os outros, com a escola e com o saber escolar (GOMES \& MORTIMER, 2008; GUTIERREZ et al, 1995; HAND, 2006; NASIR, 2002; SOLOMON, 2007).

Muitas vezes, as relações assimétricas que se estabelecem no contexto de sala de aula - entre o professor competente, que transmite aos alunos conhecimento único e superior, que define o que é conhecimento válido e o que é aprender, e o aluno que nada sabe - não permitem criar contextos securizantes, em que o erro seja entendido como um passo de um processo e em que o aluno sinta que a sua experiência e o seu contributo são valorizados (CORNELIUS, 2004; GUTIERREZ et. al, 1995; PERRET-CLERMONT, 2004). Em muitos casos, através de interacções quotidianas na sala de aula, e no jogo de expectativas, responsabilidades e deveres e formas de interpretar a realidade e o outro, os alunos constroem identidades escolares negativas, que podem afectar a forma como ele irão relacionar-se com a escola e com o saber escolar (ZITTOUN, 2004). 
Ao desenvolver práticas que permitam ao aluno expressar a sua experiência, considerá-la, recordá-la, aprender a partir dela e a planear novos caminhos a partir dela (PERRET-CLERMONT, 2004), está-se a modificar as relações de poder na sala de aula, facilitando a participação activa dos alunos e a reconstrução das suas identidades escolares (CORNELIUS, 2004; GUTIERREZ et. al, 1995). As actividades investigativas na sala de aula permitem não só criar contextos em que as identidades escolares dos alunos podem ser reconstruídas, mas também contextos de maior envolvimento com o saber e com a aprendizagem (FREIRE et al, 2009a; FREIRE et al, 2009b).

\section{ACTIVIDADES INVESTIGATIVAS NA SALA DE AULA}

No contexto actual, de grande exigência, por um lado, para se aumentar a literacia científica e, por outro lado, de desligamento dos jovens pelos saberes escolares, e em particular, pelas Ciências, torna-se essencial envolver os alunos nas suas próprias aprendizagens, torná-los conscientes da relevância desses saberes para as suas necessidades. Para promover a literacia científica é necessário proporcionar aos alunos um ambiente de aprendizagem em que eles sejam encorajados a explorar, a testar as suas ideias, a recolher evidências, a interpretar com base nas evidências recolhidas, a tomar decisões e a encontrar uma solução para os problemas que lhes são propostos (MARTINS, 2003).

Vários autores têm sugerido a utilização de actividades investigativas nas aulas de Física e Química como forma de envolver os alunos nas aulas e criar oportunidades equitativas de sucesso (NRC, 1996; WOOLNOUGH, 1998). Com efeito, as actividades investigativas na sala de aula envolvem um raciocínio complexo e um elevado empenho por parte dos alunos (TRIGO-TEIXEIRA, 2003) e podem ser exploradas através de questões mais abertas ou mais fechadas, introduzidas por uma questão ou problema para a qual os alunos desconhecem a solução (GOMES et al, 2008; WOOLNOUGH, 1998). De acordo com Ash e Klein (2000), as actividades investigativas envolvem processos de exploração dos materiais e do mundo material e exigem curiosidade, interesse e perseverança para compreender e resolver o problema. Segundo estes autores, aprende-se colocando questões e fazendo previsões, formulando hipóteses e criando modelos ou teorias. Para Carlson, Humphrey e Reinhardt (2003), as actividades investigativas na sala de aula envolvem, de uma forma activa, os alunos na procura do caminho a seguir para encontrar uma ou mais soluções, tratando-se de uma metodologia que tem a potencialidade de promover a compreensão dos fenómenos e o desenvolvimento de competências de conhecimento processual, raciocínio e comunicação, entre outras. Estas potencialidades permitem dar resposta às exigências do mundo actual (LERDERMAN, 2006). 


\section{METODOLOGIA}

\section{Contexto do estudo e participantes}

Este estudo faz parte de um projecto mais amplo que teve como objectivos, entre outros: (i) conhecer práticas promotoras de sucesso educativo em escolas marcadas pelo absentismo, fracasso escolar, desmotivação dos seus alunos, e (ii) conhecer estratégias de ensino/aprendizagem no ensino das Ciências capazes de envolver todos os alunos nas suas próprias aprendizagens e de promover, em todos, a literacia científica. Especificamente com o estudo apresentado no presente artigo pretendemos conhecer o impacte que as actividades investigativas na sala de aula tiveram a nível dos alunos pertencentes a um curso de Educação e Formação.

No seu percurso de desenvolvimento profissional, a professora de Físico-Química envolvida neste estudo confrontou-se com as actividades investigativas na sala de aula, que estudou numa perspectiva investigação na própria prática (BAPTISTA \& FREIRE, 2006; SAGOR, 2005). Em consonância com as orientações curriculares e cortando com práticas mais tradicionais (SAGOR, 2005), esta professora passou a incluir, na sua prática corrente, este tipo de actividades.

As actividades investigativas foram implementadas em grupo e seguiram um ciclo de aprendizagem formado por cinco estádios: envolver, explorar, explicar, elaborar e avaliar (BYBEE et al, 2006). Este ciclo de aprendizagem inicia-se com a fase Envolver, na qual o professor apresenta aos alunos uma situação problemática, com recurso a livros, textos e/ou imagens. Este constitui um momento importante para motivar os alunos, i.e., para os levar a querer aprender um tema específico. Depois de activado um certo estado motivacional, o professor passa para a segunda fase Explorar, que consiste em planificar uma actividade com vista a responder à pergunta inicial e em implementar essa actividade de acordo com o plano. Durante a fase Explicar os alunos têm que discutir os resultados obtidos e considerar evidências, para chegarem a uma conclusão (resposta à pergunta inicial). De seguida, na fase Elaborar, é pedido aos alunos para "irem mais além...", dando um título à actividade, fazendo uma pesquisa mais aprofundada sobre o tema e/ou levantando novas questões relacionadas com o tema e, por último, na fase Avaliar os alunos têm que reflectir sobre o que aprenderam, sobre como aprenderam e sobre o que gostariam de aprender mais.

\section{Participantes}

Os alunos estudados pertencem a um curso de Educação e Formação - Electricistas de Instalações, que frequentam o $10^{\circ}, 11^{\circ}$ e $12^{\circ}$ anos de escolaridade. Perfazem um total de 28 participantes, todos do sexo masculino, com ida- 
des compreendidas entre os 16 e 20 anos. De um modo geral, são alunos com histórias repetidas de insucesso escolar, alguns dos quais estavam em risco de abandono escolar. É de referir a taxa de desistência bastante elevada neste curso de Educação e Formação. Com efeito, matriculam-se no $10^{\circ}$ ano, neste curso de Educação e Formação, em média, cerca de 15 a 20 alunos e, no primeiro período, cerca de metade abandona o curso. Existe uma maior percentagem de abandono do $10^{\circ}$ para o $11^{\circ}$ ano, sendo que entre $11^{\circ}$ ano e o $12^{\circ}$ o número de alunos mantém-se. Os alunos participantes do estudo pertencem a três turmas diferentes, referentes aos três anos de escolaridade e que frequentam a disciplina de Física e Química. No final do ano, o número de alunos por turma era reduzido: 12 alunos na turma do $10^{\circ}$ ano de escolaridade, 6 na turma do $11^{\circ}$ e 10 na turma do $12^{\circ}$ ano.

\section{Recolha dados}

Os dados foram recolhidos através da entrevista em grupo focado (FREY \& FONTANA, 1998; KRUEGER, 1994; MORGAN, 1998) com os objectivos de: (i) conhecer a sua história escolar; ii) explorar o modo como os alunos vivenciaram a sua experiência no curso de Educação e Formação e, especificamente, como viveram as actividades investigativas nas aulas de Ciência, e (ii) conhecer o impacte que esta prática e o contexto escolar tiveram a nível do modo como se percepcionam enquanto alunos e como pensam que os outros os percepcionam, e a nível da sua percepção das aulas de Física e Química e da escola. Foram realizadas cinco entrevistas em grupo focado, sendo os grupos formados tendo em conta os grupos de trabalho da sala de aula. Assim, relativamente ao $10^{\circ}$ e $12^{\circ}$ anos de escolaridade constituíram-se, para cada ano, dois grupos de seis e cinco alunos, respectivamente, e para a turma do $11^{\circ}$ ano formouse apenas um grupo. Os participantes constituíam grupos homogéneos, no que diz respeito a variáveis como experiência escolar passada e presente. As entrevistas foram marcadas de acordo com a disponibilidade dos alunos entrevistados, sendo estas gravadas recorrendo a um registo áudio e transcritas na íntegra.

\section{Análise dos dados}

Consistente com o paradigma da investigação naturalista adoptado (BOGDAN \& BIKLEN, 1994), para estudar a qualidade e tipo de respostas dadas, bem como os argumentos apresentados pelos alunos, utilizámos um método de análise de conteúdo, recorrendo a categorias teóricas previamente definidas. Estas categorias foram definidas tendo em conta resultados de estudos iluminando a interrrelação entre processos identitários e a relação com a escola, com os outros agentes e com o saber escolar (FREIRE et al, 2009a, 2009b; GOMES \& MORTIMER, 2008; MATTOS, 2005; SMITH, 2006) e tendo em conta o objectivo do presente estudo. As categorias de análise utilizadas 
foram as seguintes: i) percurso escolar e percepção sobre a escola; ii) expectativas em relação ao curso; iii) identidades escolares; e iv) percepção do curso de Educação e Formação e das aulas de Física e Química.

\section{RESULTADOS}

Os resultados obtidos foram organizados de acordo com as categorias de análise apresentadas.

\section{Percurso escolar e percepção sobre a escola}

De uma maneira geral, os alunos relatam histórias pesadas de insucesso escolar (18 alunos afirmaram que já tinham reprovado, alguns mais do que uma vez) e alguns deles revelam trajectórias passadas marcadas por um grande desligamento em relação à escola e, alguns alunos, mesmo de alheamento em relação à escola. Este sentimento está bastante marcado na fala de um aluno que afirma que "Não sei bem, para que é que isto serve [curso de Educação e Formação]. Se calhar ainda me vou embora. Eu não gosto muito disto... A escola e eu não nos entendemos" (A7) ou de um outro que afirma que "Sinto que ando perdido... Só quero fazer isto [terminar a escolaridade], para depois ir fazer outras coisas. Mas, outras vezes tenho vontade de vir, mas não de aprender! Tenho a cabeça noutro sítio, distraio-me para o tempo passar" (A5).

O desligamento em relação à escola está associado ao desinteresse pelas matérias e pelo estudo, às dificuldades em aprender e a experiências constantes de insucesso, e a práticas pedagógicas transmissivas que não lhes permitem descortinar um sentido para aquilo que aprendem (Quadro 1).

Quadro 1 - Imagem da escola e aspectos negativos que lhe estão associados.

\begin{tabular}{c|c|c|c} 
& $\mathbf{1 0 ^ { \circ }}$ ano $(\mathbf{n}=\mathbf{1 2})$ & $\mathbf{1 1 ^ { \circ }}$ ano $(\mathbf{n}=\mathbf{6})$ & $\mathbf{1 2}^{\mathbf{0}}$ ano $(\mathbf{n}=\mathbf{1 0})$ \\
\hline $\begin{array}{c}\text { Falta de gosto por estudarl } \\
\text { desinteresse pelas matérias }\end{array}$ & 12 & 6 & 4 \\
\hline $\begin{array}{c}\text { Dificuldades em aprender } / \\
\text { experiência constante de insucesso }\end{array}$ & 7 & 1 & \\
\hline Práticas pedagógicas dos professores & - & 4 & 3
\end{tabular}

Relembrando a sua experiência passada, dois grupos de alunos descrevem as práticas pedagógicas e as matérias sem interesse veiculadas na escola regular.

A1 - ... Mas, antes de entrar para o curso era uma seca. Eu acho que não gostava de...

A3 - As actividades muito teóricas, eu não gostava. Também sentia algumas dificuldades. Não gosto muito de ler textos. 
A2 - As matérias eram desinteressantes, sem interesse. No curso estamos mais orientados para aquilo que gostamos. Eu sempre gostei de electricidade.

A20 - As aulas eram muito chatas. Atirava papéis com a caneta...

A19 - Tirando a Educação Física, o resto era tudo muito chato. Tudo muito teórico. Não gosto disso...

A21 - Pois, só ler...

As respostas dos alunos às questões sobre os motivos que os levaram a optar por frequentar o curso de eEucação Formação e se já pensaram abandonar a escola no passado revelam também alguns dos aspectos negativos associados à escola.

“... se este ano correr mal, eu vou-me embora. Não gosto da escola. É só estudar. Ando aqui a fazer um favor aos meus pais". (A6)

"Quando uma pessoa até estuda e se esforça, se esforça, se esforça e não compreende... isto desmotiva. Por muito que goste da escola, chega a uma altura que acho que não quero mais". (A15)

"Estaria a mentir se dissesse que não [relativamente a abandonar a escola]. Ninguém gosta de chumbar, fica-se deprimido, sem vontade. E é preciso ter vontade". (A13)

A par desta percepção negativa da escola, os alunos também revelam apreciações bastante favoráveis no que diz respeito à dimensão afectiva e social da escola. Alguns alunos descrevem-na mesma como a sua casa. "Passado tanto tempo, a escola é a minha casa. Ya! Eu só uso, na minha casa, a cama e como o jantar...”. Outro aluno aponta o mesmo aspecto: “... a escola é a minha primeira casa. A minha casa é só para dormir, quase. Aqui, é onde fico mais tempo acordado. Mas, às vezes não me apetece vir! Isto é chato. As disciplinas podiam ser melhores" (A4). É evidente, neste exemplo, a clivagem que o aluno faz da escola: boa e má. Boa associada a experiências afectivas e sociais positivas e má associada ao estudo, ao desinteresse e a experiências de insucesso. Este carácter duplo está bem patente nas respostas de muitos alunos. Um aluno descreve a escola da seguinte forma: "Sinto que a escola é um sítio fixe, mas só é pena estudar" (A24). Com efeito, para a maior parte dos participantes ( $n=19)$, a escola é, também, um espaço onde gostam de estar, porque convivem, têm os seus amigos e se divertem, sendo esse um motivo acrescido que torna difícil a decisão de abandonar a escola e porque optaram por seguir esta modalidade de ensino, tal como nos revelam alguns excertos.

"Quando uma pessoa já tem um dinheirinho só para ela, pensa em ter mais. Mas a escola, e esta até tem condições, é importante... para saber mais, para fazer amigos e até, para nos chatear". (A20) 
"Às vezes, apetece-me ficar a dormir, mas por causa das faltas venho. A escola é boa por causa dos amigos e saímos juntos a noite”. (A1)

"A escola até tem piada nos intervalos... E quando as coisas são mais práticas". (A12)

A escola é, pois, percepcionada segundo uma dupla vertente: a vertente da aprendizagem (dimensão cognitiva) e as dificuldades que coloca a estes alunos e que lhe suscita vontade de abandonar a escola, mas também a vertente social e afectiva, associada ao prazer de estar com os outros e de fazer amizades, que se contrapõe à vontade de abandonar a escola. Assim, não obstante as percepções negativas em relação à escola e a avaliação negativa da sua experiência continuada na escola e, apesar de muitos deles já terem considerado a hipótese de abandonar a escola $(n=15)$, os alunos optaram por ingressar neste curso. Como um aluno se define "somos os sobreviventes!" (A4).

\section{Expectativas em relação ao curso de Educação e Formação}

Os motivos que apontam para terem optado pelo curso de Educação e Formação são variados. Alguns alunos revelam uma escolha pouco pensada, pouco reflectida, muitas vezes, resultado de pressões familiares ou da influência de amigos e/ou professores, para fugir de experiências negativas ou ainda por falta de alternativas. Outros, pelo contrário, fazem esta opção em busca de novos caminhos (saídas profissionais e académicas futuras) ou pelo interesse que este curso específico (Electricistas de Instalações) lhes suscita. Em quase todos eles, são preponderantes também as expectativas de serem bem sucedidos e de encontrarem novas práticas pedagógicas mais atraentes (Quadro 2).

Quadro 2 - Motivos para a escolha do curso e expectativas.

\begin{tabular}{|c|c|c|c|}
\hline & $10^{\circ}$ ano $(n=12)$ & $11^{\circ}$ ano $(n=6)$ & $12^{\circ}$ ano $(n=10)$ \\
\hline $\begin{array}{l}\text { Pressões familiares / } \\
\text { influência de amigos e/ou professores }\end{array}$ & 3 & $\cdot$ & $\cdot$ \\
\hline Fuga de experiências escolares negativas & 6 & 3 & 5 \\
\hline Falta de alternativas à escola & 2 & $\cdot$ & 1 \\
\hline $\begin{array}{l}\text { Busca de novos caminhos } \\
\text { (saída profissional/ continuação dos estudos) }\end{array}$ & 2 & 5 & 2 \\
\hline Interesse pelo curso de Electricistas de Instalações & 1 & 3 & 2 \\
\hline Expectativas de sucesso & 8 & 5 & 4 \\
\hline Expectativas de novas práticas pedagógicas & 3 & - & $\cdot$ \\
\hline
\end{tabular}

Tal como já foi referido, uma maneira geral, os alunos transparecem uma atitude passiva em relação à opção por este curso específico de Educação e Formação (Electricistas de Instalações). Para muitos, esta opção é pouco reflectida, nalguns casos, sendo o resultado de pressões familiares ou da falta de alternativas à escola, tal como o iluminam os seguintes exemplos. 
"Já tenho 19 anos e já tenho idade para trabalhar. Quando reprovei pensei em abandonar e, depois, no primeiro ano deste curso. Mas depois, lá passei e até gosto. O meu irmão não me deixava desistir. Ele é mais velho e já anda na universidade”. (A2)

"Já pensei, mas eu até gosto. E depois, se eu não andasse aqui para onde ia? ...E lá está, sem estudos é mais difícil arranjar um emprego". (A8)

Assim, para muitos alunos o curso de Educação e Formação não surge no âmbito de um projecto escolar ou de um projecto de vida, tal como se pode observar no seguinte diálogo.

Entrevistador - Porque optaram por fazer este curso de Educação e Formação?

A17 - Eu cheguei a isto no ano passado, quando andava no ciclo.

A13 - Eu reprovei já algumas vezes e, então, achei que seria bom vir para aqui.

A18 - Eu também. Foi porque reprovei.

A14 - Sim. Quando uma pessoa já não pode mais com os chumbos, toma opções.

A15 - Eu vim porque o meu pai trabalha nos cavalos com o professor Y, que achou que era bom para mim. Ele é nosso professor.

Este surge-lhes como uma saída imediata para as suas dificuldades, como uma alternativa aos insucessos recorrentes e, para alguns, como alternativa à desistência da escola. Por exemplo:

“Para não abandonar é que deixei o ciclo e vim para aqui!” (A17)

"Foi um bocadinho difícil [tomar a decisão de ingressar no Curso], porque gostava de continuar a estudar no normal. Já não queria era reprovar mais". (A12)

“Eu vim porque reprovei uma vez. E não gosto de tirar negas". (A26)

"Eu andei dois anos no $10^{\circ}$ ano e achei que não conseguia. Precisava de coisas mais práticas. A Físico-Química era uma miséria e a Matemática um nulo". (A2)

Noutros casos, os alunos optam por este curso de uma forma positiva, porque têm interesse pelo curso, porque está associado a maiores saídas profissionais (ou académicas), ou porque é uma forma de viverem experiências de sucesso, uma vez que o percepcionam como sendo mais fácil e mais prático.

“... Vim para aqui porque chumbei e porque electricidade me pareceu um bom nome para poder mais tarde trabalhar”. (A23)

"Eu já fazia umas coisas com ares condicionados e quando ouvi isto... pensei, vou para lá!” (A20) 
"Estamos bem aqui! Eu acho que a escola é um caminho fixe. Não sei, mas se tivesse cabeça gostava de continuar a estudar! Claro que também quero ter filhos, mas gostava de ir para a faculdade". (A18)

"Eu no $9^{\circ}$ ano pensei logo noutra coisa para fazer. Mas depois decidi continuar, mas queria uma coisa fácil”. (A9)

"Eu também não gostava de estudar aquelas matérias no $5^{\circ}$ ano e, depois, no $7^{\circ}$ ano pensei que isto dos cursos era mais fácil”. (A1)

“Eu não gosto de estudar e, então vim aqui para ver se era mais fácil”. (A25)

É como se fosse mais uma oportunidade que os alunos concedem a si mesmos, uma oportunidade de serem bem sucedidos. De uma maneira geral, as suas avaliações sobre o seu percurso na escola e sobre os motivos que os levam a optar por esta modalidade de ensino remetem para percepções sobre si mesmos negativas.

\section{Identidades escolares}

Muitos destes alunos apresentam percepções negativas sobre si mesmos, de que o seguinte diálogo é revelador.

Entrevistador - Porque vieste para este curso?

A5 - Porque sou burro.

A4 - Somos todos!

A3 - Cada um fala por si

A4 - Diz lá que gostas de estudar? Eu cá gosto da prática e vim para este curso por causa da prática! Eu gosto de fios e de ver as coisas.

Um outro aluno usa igualmente termos depreciativos para se descrever: “... A Físico-Química era uma miséria e a Matemática um nulo” (A2). Noutros casos, a descrição que fazem de si enquanto alunos revela um sentimento de impotência de ser bem sucedido, tal como o ilustram os seguintes exemplos.

“Eu não dava muito para estudar, estudar, estudar...”. (A5)

"Se tivesse cabeça gostava de continuar a estudar". (A18)

"Tenho pena de não ser melhor aluno, porque não consigo". (A27) 
Noutros alunos, ressalta o sentimento de tristeza e de desânimo associado às suas experiências escolares negativas e às reprovações. Um aluno afirma: "Espero continuar sem negas, porque quando as vejo fico muito triste" (A8). Outro refere que “... é difícil chumbar e não conseguir melhorar. Penso logo que era melhor deixar" (A25).

Estas identidades foram sendo construídas ao longo de um percurso escolar marcado por insucessos. A própria opção actual pelo curso de Electricistas de Instalações surge associado a essas mesmas identidades. Com efeito, o ser prático e o ser mais fácil, e, logo, permitir aos alunos viver experiências de sucesso são argumentos frequentemente apresentados pelos alunos para justificarem a escolha do curso. Mas, estes mesmos argumentos são usados para justificar as percepções (negativas) que eles pensam que os colegas associam a eles. Quando questionados sobre o que pensam que os colegas e professores pensam deles, alguns alunos referem elementos negativos, tal como o ilustram os seguintes exemplos e diálogo.

"Acho que para os outros não somos lá muito bem vistos, porque isto é mais fácil. Mas, eu quero é ter o $12^{\circ}$ ano". (A16)

"Os outros colegas não [nos veem] lá muito bem. Acham que não conseguimos e já reprovámos”. (A21)

“...Veem-nos como os dos cursos e se acontece alguma coisa, fomos sempre nós”. (A1)

“Às vezes, ouvimos umas bocas dos outros, mas eu não me importo". (A26)

"Eu já fui gozado pelos betos. Lá vai o electricista" (A3)

Entrevistador - O que pensam os restantes alunos da escola sobre vocês?

A3 - Pensam que não sabemos nada e que não somos capazes.

A1 - Mas, eu acho que os professores facilitam.

A3 - Eu acho que não. Já viste quanto tempo estamos aqui?

A5 - Ah! Lá isso concordo: muito tempo!

A6 - Os outros consideram-nos à parte.

A2 - E estamos... o pavilhão até é diferente. Um só para nós.

A3 - Mas quando entrei para o quadro de honra foi diferente. E este ano vou outra vez!

Se, por um lado, o curso de Electricista de Instalações lhes surge como uma alternativa à sua experiência de insucesso, por outro lado, este tem conota- 
ções negativas: ser aluno do curso significa ser mau aluno, ter repetido de ano sucessivas vezes, saber menos, ter menos capacidades e, mesmo, ser desacreditado nas situações de sucesso. Esta conotação negativa associado ao curso de Educação e Formação afecta as identidades escolares dos alunos.

Contudo, é de referir que a frequência deste curso não tem uma conotação negativa para todos os alunos. Com efeito, à medida que alguns alunos vivem experiências de sucesso desenvolvem-se neles crenças de que são capazes. Alguns dos alunos confrontam-se, mesmo, com novas possibilidades em relação a eles próprios. Nos diálogos que mantêm entre si sobressai esta tensão, este confronto entre auto-percepções escolares negativas e elementos positivos oriundos da sua experiência escolar presente.

Entrevistador - O que pensam os restantes alunos da escola sobre vocês?

A6 - Eu acho que os outros me veem na mesma. Às vezes, somos discriminados porque somos electricistas.

A5 - Pois, temos sempre aquele sentimento de sermos inferiores.

A3 - Deixa-te de coisas. Eu fui para o quadro de honra.

A1 - Pois, mas isso és tu. Os outros veem-nos como os dos cursos e se acontece alguma coisa, fomos sempre nós.

Entrevistador - O que pensam os restantes alunos da escola sobre vocês?

A12 - Nem gostam, nem desgostam.

A10 - É isso que tu achas? Eu acho que eles nos acham uns burrinhos.

A7 - Achas que não? Já reprovámos algumas vezes! Nas reuniões que há devem dizer coisas como: estes não aprendem nada e são uma má influência cá na escola!

A9 - Não exageres!

Nos diálogos que mantêm entre si, há como que um negociar das suas identidades escolares negativas, numa tentativa de introduzir novos elementos que lhes permita percepcionar-se de uma outra forma. Tal como refere um aluno, agora “já nos veem de outra forma!” (A3). Mas são os outros que os percepcionam de outra forma ou são os próprios alunos que se começaram a percepcionar de outra forma? E o que mudou? 


\section{Percepção sobre o curso de Educação e Formação e das aulas de Física e Química}

Uma característica evidente dos discursos dos alunos é ser bastante marcado por um antes e um agora. Antes do curso: quando chumbava, quando não aprendia, quando as matérias não tinham interesse e eram muito teóricas. Com efeito, ao longo do seu percurso escolar, a escola foi-se constituindo enquanto espaço no qual os alunos, constantemente, eram confrontados com as suas incapacidades e dificuldades. Tal como refere um aluno:

\footnotetext{
"Cada vez a saber menos e a detestar a escola. Quando andei no ciclo, achei mesmo uma porcaria. Todos os dias pensava: Não vou, não vou porque não quero. Ia chumbando por faltas. Agora, já gosto mais”. (A25)
}

Agora, com a frequência no curso e com a vivência de experiências de sucesso, os alunos sentem-se capazes de fazer algo e, para alguns, o leque de possibilidades abriu-se, mesmo.

“Eu não dava para estudar, estudar, estudar... Assim, gosto mais, é melhor”. (A5)

"Eu sinto-me bem porque agora consigo fazer tudo e não ter negativas". (A2)

"Eu já pensei em abandonar, mas agora que eu estou a acabar isto, penso em continuar. Não é esquisito?” (A22)

"Mas já pensei em sair. Mas, agora quero acabar o $12^{\circ}$ ano para ter um emprego melhor". (A5)

A escola funcionava como um espaço que não lhes permitia restaurar a sua confiança e redefinir a sua identidade escolar. Contudo, com a sua entrada no curso de Educação e Formação, os alunos começaram a viver experiências de sucesso, que lhes permitiu reavaliar a sua própria identidade escolar e, do mesmo modo, rever a sua imagem da escola e dos saberes escolares, que passaram a avaliar de modo mais positivo.

Esta dimensão temporal é, também, bastante evidente nas respostas de alguns alunos em relação às aulas de Física e Química. O que mudou? Não só os alunos contactaram com experiências pedagógicas distintas (as actividades investigativas), que lhes permitiram desenvolver outras formas de trabalhar, como também esta nova forma de organizar o processo de ensino-aprendizagem e de aprender, lhes permitiu viver situações de sucesso, tal como se pode observar nos diálogos apresentado em baixo.

A12 - O tipo de aulas mudou, o que é bom. São mais práticas.

A7 - Sim. Como o A12 diz, se for mais prático, nós gostamos e sentimo-nos logo melhor. Mais, gosto de vir para aqui. Não é chato. 
A9 - Esta coisa de sermos nós a fazer é diferente de ver. Estar a alguém a falar 90 minutos, é muito chato. Só dá vontade de me portar mal.

A11 - ... Eu não gosto, como já lhe disse, muito da escola. Mas podermos fazer coisas... É das coisas que nos interessam.

A12 - Motiva mais. Pensamos: vou à aula porque vou saber mais e gosto. Dá gosto aprender e não é aborrecido.

A1 - Claro que estas actividades nos ajudam a compreender a matéria. Veja se a professora passasse as aulas a falar, falar, falar...

A2 - ... ninguém a ouvia e só queríamos ir embora. Ninguém aprendia.

A3 - Assim não. Gostámos das aulas e as actividades deram-nos hipóteses de relacionarmos esta disciplina com a nossa vida.

A4 - Foi bom aprendermos assim a matéria.

Mudou a possibilidade de planearem e fazerem experiências, de se envolverem com a sua própria aprendizagem, de compreenderem mais facilmente, de verem uma relação com a sua própria vida e de trabalhar em grupo. Para além disso, esta mudança possibilitou-os aprender, viver experiências de sucesso e desenvolver um sentimento de que conseguem, de facto, aprender. Como refere um aluno: "São como eu gosto [as aulas de Física e Química]: práticas e podemos descobrir a matéria e falar com os nossos colegas sobre o que aprendemos" (A24).

\section{DISCUSSÃO}

Perante a nova opção escolar (frequência de cursos de Educação e Formação), os participantes deste estudo decidiram permanecer na escola, em busca de experiências escolares diferentes. As actividades investigativas nas aulas de Física e Química permitiram-lhes viver experiências de aprendizagem diferentes, nas quais não só assumiram maior responsabilidade pelo próprio processo de aprendizagem (novas formas de se relacionar com o saber escolar), como também ensaiaram novas formas de se relacionar com os outros e com o professor. Este contexto inovador de aprendizagem parece facilitar a criação de "espaços de pensamento", nos quais os alunos podem reflectir sobre a sua experiência presente (académica, social e pessoal) (PERRET-CLERMONT, 2004), permitindo-lhes explorar novos sentidos, nomeadamente, sobre quem são como alunos e, assim, restaurar aspectos mais negativos da sua identidade escolar. Esta experiência é essencial para que os alunos voltem a reinvestir na escola, caso contrário irão procurar outros contextos (fora da escola) onde possam (re)construir identidades (ARCHER et al, 2007; FLORES-CRESPO, 2007; ZITTOUN, 2004) 
ou irão desenvolver formas de relacionamento com a escola desinvestidas, mas que lhes permitem proteger as suas identidades (FREIRE et al, 2009a).

É de salientar, no entanto, que o processo de reconstrução das suas identidades escolares não é linear, nem simples. Com efeito, as próprias identidades escolares que estes alunos foram construindo acerca deles próprios ao longo do seu percurso escolar parecem afectar a maneira como percepcionam as suas experiências presentes e como pensam que os outros os percepcionam, colocando constrangimentos ao próprio processo de reconstrução identitária. Nalguns destes alunos é evidente a tensão entre dois tipos de elementos opostos - identidades negativas construídas ao longo do percurso escolar e experiências recentes de sucesso, e a dificuldade em integrar estes dois elementos numa identidade reconstruída.

As identidades são construídas em comunidades de prática, nas quais os sujeitos ocupam posições, que lhes permitem níveis de participação distintos na negociação de sentidos e na interpretação das experiências no seio dessas mesmas comunidades (WENGER, 1998). A implementação de actividades investigativas nas aulas de Física e Química permitiu criar um contexto de participação distinto na comunidade-turma, que possibilitou aos alunos negociar e explorar novos sentidos para a sua experiência. Contudo, na comunidade prática mais ampla que é a escola, os alunos são ainda reificados em posições que lhes dificultam participar na negociação de definições sobre eles próprios, definições essas que lhe são impostas (“os alunos CEF”). A grande questão que se coloca é como desafiar estas posições que lhe foram impostas? Será que a mudança observada nas aulas de Física e Química afecta todo o contexto escolar mais amplo? E de que forma? Estas são questões relevantes que ficam por responder, sendo, no entanto, necessário recurso a outro tipo de estudos, na qual a dimensão temporal seja considerada.

\section{CONCLUSÃO}

As evidências recolhidas no âmbito deste estudo iluminam-nos dois aspectos principais: (1) um percurso inicial feito de insucessos e assente em identidades escolares negativas, que não sendo passíveis de ser restauradas, geram vontade de abandonar a escola; (2) o impacte que uma nova experiência curricular e pedagógica (a entrada para um curso de Educação e Formação e as actividades investigativas na sala de aula de Física e Química) pode ter no processo de reconstrução dessas identidades escolares.

Este estudo vem assim chamar a atenção para importância de se facilitar contextos que permitam a reconstrução de novas identidades escolares, que possibilitem ao aluno acolher experiências de sucesso e dar um novo sentido à escola e aos saberes escolares, remetendo-nos para a prática dos professores. É essencial que os contextos de ensino-aprendizagem mudem de facto. As orien- 
tações curriculares previstas para os cursos de Educação e Formação predispõem para mudanças nas práticas dos professores (Despacho Conjunto n. 453/2004, de 27 de Julho). Mas os professores têm que estar predispostos a romper com práticas mais tradicionais (SAGOR, 2005), caso contrário corre-se o risco dos professores mudarem aspectos periféricos das suas práticas (FULLAN, 2001), sem um impacte significativo no contexto de participação na sala de aula. Por exemplo, o desenvolvimento de actividades investigativas, de forma fechada, sem espaço para os alunos as conceberem ou implementarem de forma autónoma, continuando o professor a ocupar uma posição privilegiada na definição do que é ser aluno, do que é aprender, e/ou do que é conhecimento válido. Os projectos de desenvolvimento profissional são, pois, essenciais. É no processo, contínuo, de formação, que, também, os professores podem encontrar o espaço de reflexão e de apoio que facilitem não só a apropriação de novos saberes e de competências, mas também outras imagens sobre o que é ser professor, sobre o que é ser aluno, ensinar e aprender, sendo que essa reflexão lhes permitirá implementar as actividades investigativas de forma, realmente, inovadora, fornecendo aos alunos verdadeiros espaços de pensamento e a possibilidade de restaurarem identidades escolares.

\section{REFERÊNCIAS BIBLIOGRÁFICAS}

AINSCOW, M. \& FERREIRA, W. Compreendendo a educação inclusiva. Algumas reflexões sobre experiências internacionais. In: RODRIGUES, D. Perspectivas sobre inclusão: da educação à sociedade. Porto: Porto Editora, 2003. p. 103-116.

ARCHER, et al. "University's not for me - I'm a Nike person": Urban working-class young people's negotiation of "style", identity and educational engagement. Sociology, v. 41, n. 2, p. 219-237, 2007.

ASH, D; KLEIN, C. Inquiry in the informal learning environment. In: MINSTRELL, J; Zee, E. Inquiry into inquiry learning and teaching in science. Washington, CA: Corwin Press, 2000. p. 216-240.

BAPTISTA, M; FREIRE, A. Investigações em aulas de Ciências Físico-Químicas. Mudança nas percepções de alunos do $8^{\circ}$ ano relativamente ao ensino e avaliação. Investigação em Educação, v. 5, p. 237-257, 2006.

BARROSO, J. Factores organizacionais da exclusão escolar. A educação inclusiva. In: RODRIGUES, D. Perspectivas sobre inclusão: da educação à sociedade. Porto: Porto Editora, 2003. p. 25-36.

BOGDAN, R. C; BIKLEN, S. K. Investigação qualitativa em Educação. Porto: Porto Editora, 1994. BYBEE, R.W. Scientific inquiry and science teaching. In: FLICK, L.B; LEDERMAN, N.G. Scientific inquiry and nature of science. Dordrecht: Springer, 2006. p. 1-14.

BYBEE, R.W, et al. The BSCS 5E instructional model: Origins, effectiveness and applications. Colorado Springs, CO: BSCS, 2006.

CANÁRIO, R. Territórios educativos de intervenção prioritária: a escola face à exclusão social. Revista de Educaşão, v. IX, n.1, p. 125-134, 2000.

CANÁRIO, R., ALVES, N; ROLO, C. Escola e exclusão social. Lisboa: Instituto de Inovação Educacional, 2001.

CARLSON, L., HUMPHREY, G; REINHARDT, K. Weaving science inquiry and continuous assessment. Thousand Oaks, CA: Corwin Press, 2003. 
CNE. Debate nacional sobre Educaşão. Lisboa: CNE, 2007.

COMISSÃO EUROPEIA. Science Education now: A renewed pedagogy for the future of Europe. Bruxelas: Directorate-General for Research Science, Economy and Society, 2007.

CONSELHO da EUROPA. The Key Competences Framenork. 2006a Disponível em: http://eurlex.europa.eu/LexUriServ/site/en/oj/2006/1_394/1_39420061230en00100018.pdf. Acesso: 21 fev. 2008.

CONSELHO da EUROPA. Progress towards the Lisbon objectives in education and training. Bruxelas: Conselho da Europa, 2006b.

CONSELHO da EUROPA. Schools for the 21st century. Bruxelas: Conselho da Europa, 2007.

CORNELIUS, L. L. Power in the classroom: How the classroom environment shapes students' relationships with each other and with concepts. Cognition and Instruction, v. 22, n.4, p. 467-498, 2004.

DENZIN, N. K. The interpretative process. In: HUBERMAN, A. M; MILES, M. B. The qualitative researcher's companions. Thousand Oaks: Sage Publications, 2002. p. 349-366.

FLORES-CRESPO, P. Ethnicity, identity and educational achievement in Mexico. International Journal of Educational Development, v. 27, p. 331-339, 2007.

FREIRE, S. et al. Identity construction through schooling: Listening to students' voices. European Educational Research Journal, v. 8, n. 1, p. 80-88, 2009a.

FREIRE, S. et al. Disengagement with school: Classroom investigations as a possible solution. Problems in Education in 21st century, v. 13, p. 44-53, 2009b.

FREY, J. H; FONTANA, A. The group interview in social research. In: MORGAN, D. L. Successful focus group: Advancing the state of the art. Newbury Park, CA: Sage Publications, 1993.

FULLAN, M. The new meaning of educational change. 3 ed. Londres: Routdlege Falmer, 2001.

GALVÃO, C. et al. Avaliação de competências em Ciências. Porto: Edições Asa, 2006.

GEPE. Educação em números - Portugal. 2010. Lisboa: GEPE, 2010.

GOMES, A. D. T. et al. Processo e conhecimentos envolvidos na realização de atividades práticas: Revisão da literatura e implicações para a pesquisa. Investigações em ensino de Ciências, v. 13, n. 2, p. 187-207, 2008.

GOMES, M.F.C; MORTIMER, E.F. Histórias sociais e singulares de inclusão/ exclusão nas aulas de Química. Cadernos Pedagógicos, v. 38, n. 133, p. 237-266, 2008.

GUTIERREZ, K. et al. Script, counterscript, and underlife in the classroom : James Brown versus Brown board of Education. Harvard Educational Review, v. 65, n. 3, p. 445-471, 1995.

HAND, V. Operationalizing culture and identity in ways to capture the negotiation of participation across communities. Human Development, v. 49, p. 36-41, 2006.

LAVE, J; WENGER, E. Situated learning: Legitimate peripheral participation. Cambridge: Cambridge University Press, 1991.

LERDERMAN, N.G. Syntax of nature of science within inquiry and science instruction. In: FLICK, L.B. \& LEDERMAN, N.G. Scientific inquiry and nature of Science. Dordrecht: Springer, 2006. p. 301-318.

KRUEGER, R. A. Focus groups. Thousand Oaks: SAGE Publications, 1994.

MARTINS, M. I. Literacia cientifica e contributos do ensino formal para a compreensão pública da Ciência. Aveiro: Universidade de Aveiro, 2003.

MATTOS, M. O conselho de classe e a construção do fracasso escolar. Educaşão e Pesquisa, v. 31, n. 2, p. 215-228, 2005

MINISTÉRIO DA EDUCAÇÃO. Currículo Nacional do Ensino Básico: Competências Essenciais. Lisboa: Ministério da Educação, 2001.

MINISTÉRIO DA EDUCAÇÃO. Decreto-Lei n. 6/2001. Lisboa: Diário da República, 2001. 7p. MINISTÉRIO DA EDUCAÇÃO. Reforma do Ensino Secundário: Documento orientador da revisão curricular Ensino Secundário. Lisboa: Ministério da Educação, 2003.

MINISTÉRIO DA EDUCAÇÃO E DA SEGURANÇA SOCIAL E DO TRABALHO. Despacho-Conjunto n. 453/2004. Lisboa: Diário da República, 2004. 9p.

MORGAN, D. L. The focus group guidebook. Thousand Oaks: SAGE Publications, 1998. 
NASIR, N. Identity, goals, and learning: Mathematics in cultural practice. Mathematical thinking and learning, v. 4, n. 2\&3, p. 213-247, 2002.

NRC. National Science Education Standards. Washington, DC: National Academic Press, 1996.

NRC. Inquiry and the national Science Education Standards. Washington, DC: National Academy, 2000.

PALINSCAR, A.S. Social constructivist perspectives on teaching and learning. Annual Review of Psychology, v. 49, p. 345-75, 1998.

PERRET-CLERMONT, A. N. Thinking spaces of the young. In: PERRET-CLERMONT, A. N. et al. Joining society. Cambridge: Cambridge University Press, 2004, p. 3-10.

RESNICK, L. B; PERRET-CLERMONT, A-N. Youth in postindustrial societies. In: PERRETCLERMONT, A.-N. et al. Joining society. Cambridge: Cambridge University Press, 2004, p. 11-25.

ROGOFF, B; LAVE, J. Everyday cognition: Its development in social context. Cambridge: Harvard University Press, 1984.

SAGOR, R. The action research guidebook. Thousand Oaks, CA: Corwin Press, 2005.

SMYTH, J. 'When students have power': student engagement, student voice and the possibilities for school reform around 'dropping out' of school. International Journal of Leadership in Education, $\mathrm{v}$. 9, n. 4, p. 285-298, 2006.

SOLOMON, Y. Not belonging? What makes a functional learner identity in undergraduate mathematics? Studies in Higher Education, v. 32, n. 1, p. 79-96, 2007.

TRIGO-TEIXEIRA, M. Trabalho laboratorial de natureza investigativa: Perspectivas de alunos sobre a sua utilização em aulas de Física no Ensino Secundário. 2003. Dissertação (Mestrado) - Faculdade de Ciências da Universidade de Lisboa, Lisboa, 2003.

UNESCO. Education for All Forum. Paris: UNESCO, 2000.

UNESCO. Open file on inclusive education. Paris: UNESCO, 2003.

WENGER, E. Communities of practice. Cambridge: Cambridge University Press, 1998.

WOOLNOUGH, B. Authentic science in schools, to develop personal knowledge. In: WELLINGTON, J. Practical work in school science. London: Routledge, 1998, p. 109-125.

ZITTOUN, T. Preapprenticeship: a transitional space. In: PERRET-CLERMONT, A. N. et al. Joining society. Cambridge: Cambridge University Press, 2004, p. 153-173.

Data de recebimento: $13 / 12 / 2010$

Data de aprovação: 09/02/2011

Data da versão final: $25 / 04 / 2011$ 